\title{
Effects of hypothyroidism on bronchial reactivity in non-asthmatic subjects
}

Siegfried Wieshammer, Fritz S Keck, Andreas C Schäuffelen, Helga von Beauvais, Herbert Seibold, Vinzenz Hombach

\begin{abstract}
The effect of hypothyroidism on nonspecific bronchial reactivity was studied in 11 patients without pulmonary disease (mean age 40 (SD 13) years) who had had a total thyroidectomy and radioiodine treatment for thyroid cancer 41 (36) months before the study. All patients were studied on two occasions, once when mildly hyperthyroid while having long term thyroxine replacement treatment and once when hypothyroid two weeks after stopping triiodothyronine for the purpose of screening for metastases. Bronchial reactivity was assessed by measuring specific airways conductance (sGaw) after increasing doses of inhaled carbachol (45-1260 $\mu \mathrm{g})$. The dose producing a 35\% decrease in sGaw ( $\left(\mathbf{P D}_{35}\right)$ was determined from the cumulative log dose-response curve by linear regression analysis. Mean baseline sGaw values were similar when the patients were hypothyroid and when they were hyperthyroid $\left(1.35(0.36)\right.$ and $1.41(0.56) \mathrm{s}^{-1}$. $\left.\mathrm{kPa}^{-1}\right)$. The interstudy coefficients of variation of baseline sGaw were higher in the thyroid patients than in a euthyroid control group (14\% versus $8 \%$ ). Geometric mean $\mathbf{P D}_{35}$ was lower when the patients were hypothyroid $(97 \mu \mathrm{g})$ than when they were mildly hyperthyroid $(192 \mu \mathrm{g})$. It is concluded that acute hypothyroidism increases nonspecific bronchial reactivity in nonasthmatic subjects.
\end{abstract}

Several studies have shown an association between hyperthyroidism and increasing severity of asthma. ${ }^{1-6}$ Treatment of hyperthyroidism has been shown to improve asthma and to attenuate the bronchoconstrictor response of asthmatic patients to inhaled histamine, ${ }^{7}$ whereas replacement therapy in hypothyroid patients may cause asthma to deteriorate. ${ }^{8-10}$ These observations are surprising at first sight because many of the effects of thyroid hormone resemble the effects of stimulation of the sympathetic nervous system.

The relation between thyroid function and non-specific bronchial reactivity is less well defined in non-asthmatic subjects but there is no evidence that thyrotoxicosis is associated with bronchial hyperreactivity. ${ }^{11-14}$ Villa et al $^{15}$ reported an inverse relation between thyroid function and bronchial reactivity to inhaled carbachol in congenitally hypothyroid nonasthmatic children. We have measured the response to inhaled carbachol in patients who had had total thyroidectomy and radioiodine treatment for thyroid cancer while they were not having replacement treatment for medical reasons and when they were mildly hyperthyroid while having long term replacement treatment. Baseline specific airways conductance (sGaw) was also determined in a euthyroid control group on two occasions to assess the interstudy variation in measurements and to find out whether a change in thyroid state affects variation in measurements of sGaw.

\section{Methods}

STUDY GROUP

We studied five men and six women aged 20-55 years who had had total thyroidectomy and radioiodine treatment for thyroid cancer 41 (SD 36) months before this study. The patients were maintained on long term therapy with thyroxine in a dosage slightly above replacement doses to suppress thyroid stimulating hormone secretion-that is, they were rendered mildly hyperthyroid. None was atopic or had evidence of pulmonary disease on the basis of history, clinical findings, chest radiograph, or results of pulmonary function tests. Only one patient smoked and except for thyroxine no drugs were being taken at the time of study. No patient had had an upper respiratory tract infection within one month of being tested. Patients with paralysis of the laryngeal nerve resulting from thyroid surgery were excluded from the study. The experimental character of this study was explained to each patient and informed consent was obtained.

\section{STUDY DESIGN}

All patients were studied on two occasions separated by 103 days on average- once while they were mildly hyperthyroid during long term replacement treatment and once while they were hypothyroid after their replacement treatment with thyroid hormones had been stopped to permit a scheduled follow up iodine-131 total body scan to screen for metastases. Thyroxine was changed to triiodothyronine five weeks before the hypothyroid study, which was carried out two weeks after triiodothyronine had been stopped. After completion of the hypothyroid study replacement treatment was started again. The hyperthyroid studies were performed when the patients had been mildly 
hyperthyroid for at least six weeks. The two studies were carried out in random order. The operator was unaware of the hormonal state of the patients.

\section{HORMONE ASSAYS}

Serum concentrations of thyroxine, triiodothyronine, and thyroid stimulating hormone were measured by radioimmunoassay. Thyroxine and triiodothyronine uptake were measured to detect any alterations in hormone binding, and the free thyroxine equivalent and free triiodothyronine equivalent were calculated. ${ }^{16}$

\section{CARBACHOL INHALATION TEST}

The patients were studied under standardised conditions at the same time of day (10 am). sGaw was determined in a constant volume plethysmograph (Jaeger, Würzburg, FRG). Test aerosols of carbachol were generated by a Sandoz 1500 nebuliser (Sandoz, Nürnberg, FRG) attached to a dosimeter (APS system, Jaeger). The breath activated dosimeter delivered an aerosol bolus of about $100 \mathrm{ml}$ a puff containing $7 \mu \mathrm{l}$ of the carbachol solution. The delivery time was 0.6 seconds. The aerosol was inhaled by slowly breathing from functional residual capacity to total lung capacity with a breath hold time of two seconds. The dosage of carbachol was increased from a starting dose of five breaths of $0.125 \%$ carbachol until sGaw had fallen by $50 \%$ or until the maximum dose of $1260 \mu \mathrm{g}$ was reached. The sequence of cumulative doses was $45,90,180,360,540,720,900$, 1080 , and $1260 \mu \mathrm{g}$. sGaw was determined two minutes after each dose and a mean value from five measurements was used. The inhalation tests were well tolerated by all subjects.

\section{INTERSTUDY VARIATION OF BASELINE SGAW IN} EUTHYROID CONTROL SUBJECTS

Baseline sGaw was measured in 11 euthyroid control subjects, aged 24-68 years, without pulmonary disease on two occasions separated by 62 days on average.

\section{DATA ANALYSIS}

The interstudy coefficients of variation of baseline sGaw were calculated for the control subjects and thyroid patients as the standard deviation expressed as a percentage of the mean for each pair of sGaw measurements. The interstudy coefficients of variation of baseline sGaw of the control subjects were compared with those of the thyroid patients by the two tailed $\mathrm{F}$ test. The cumulative dose producing a $35 \%$ fall in sGaw $\left(\mathrm{PD}_{35}\right)$ was obtained from the log dose-response curve by linear regression analysis. Geometric mean $\mathrm{PD}_{35}$ values were calculated. ${ }^{17}$ The $\mathrm{PD}_{35}$ values were compared by the two tailed Wilcoxon signed rank test for paired observations after $\log$ transformation. A p value of less than 0.05 was considered statistically significant. The results are given as arithmetic means with standard deviations in parentheses unless it is stated otherwise.
Table 1 Mean (SD) concentrations of serum thyroid hormones when the patients were hypothyroid two weeks after triiodothyronine had been stopped and when they were subclinically hyperthyroid during thyroxine replacement treatment

\begin{tabular}{|c|c|c|}
\hline & Hypothyroid & Hyperthyroid \\
\hline Total T4 $(\mathrm{nmol} / \mathrm{l})$ & $15(15)$ & $164(48)$ \\
\hline $\mathrm{FT}_{4} \mathrm{E}$ & $0.20(0.17)$ & $4.0(0.9)$ \\
\hline Total T3 $(\mathrm{nmol} / \mathrm{l})$ & $0.57(0.39)$ & $1.93(0.28)$ \\
\hline $\mathrm{FT}_{3} \mathrm{E}$ & $6(4)$ & $41(6)$ \\
\hline $\mathrm{TSH}_{\mathrm{B}}(\mathrm{mU} / \mathrm{l})$ & $46(29-73)$ & $0.03(0.01-0.19)$ \\
\hline $\mathrm{TSH}_{\mathrm{S}}(\mathrm{mU} / \mathrm{l})$ & $81(54-121)$ & $0.13(0.04-0.44)$ \\
\hline
\end{tabular}

T4 - thyroxine (normal 51-154 nmol/1); $\mathrm{FT}_{4} \mathrm{E}$-free thyroxine equivalent (normal 1.53-4.12); T3-triiodothyronine (normal 1.23-2.76 nmol/1); $\mathrm{FT}_{3} \mathrm{E}$ - free triiodothyronine equivalent (normal 15-67); TSH -basal thyroid stimulating hormone (normal $0.1-4 \mathrm{mU} / 1) ; \mathrm{TSH}$ (normal $0 \cdot 1-4 \mathrm{mU} / 1$ ); $\mathrm{TH}_{\mathrm{s}}$ - thyroid stimulating hormone 20 thyrotrophin releasing hormone (normal $2-30 \mathrm{mU} / \mathrm{l}$ ).

\section{Results}

THYROID STUDIES

The hormone data for the patients when hypothyroid and mildly hyperthyroid are shown in table 1 . The mean daily dose of thyroxine required to cause suppression in the thyrotrophin releasing hormone test was 200 (SD 53) $\mu \mathrm{g}$ (range 150-350 $\mu \mathrm{g}$ ).

BASELINE PULMONARY FUNCTION

There was little difference in mean baseline pulmonary function values in the patients when they were hypothyroid and mildly hyperthyroid (table 2), and no change in mean baseline sGaw with change in thyroid state. Fairly pronounced variations in sGaw were seen between studies in individual patients (table 3). The interstudy coefficients of variation of baseline sGaw were greater in the thyroid patients (mean $14 \%$, range $2-28 \%$ ) than in the control group (mean $8 \%$, range $1-$ $18 \%)(\mathrm{p}<0.05)$.

\section{CARBACHOL INHALATION TESTS}

A $\mathrm{PD}_{35}$ value was obtained on all but one occasion. On this occasion the response was less than $35 \%$ after the maximum dose of carbachol had been given, so a value of $1260 \mu \mathrm{g}$ was assigned. Geometric mean $\mathrm{PD}_{35}$ was lower in the patients when they were hypothyroid $(97 \mu \mathrm{g})$ than when they were mildly hyperthyroid $(192 \mu \mathrm{g})(\mathrm{p}<0.05 ;$ table 3$)$.

Table 2 Mean (SD) baseline pulmonary function values when the patients were hypothyroid two weeks after triiodothyronine had been stopped and when they were subclinically hyperthyroid during thyroxine replacement treatment

\begin{tabular}{|c|c|c|}
\hline & Hypothyroid & Hyperthyroid \\
\hline $\begin{array}{l}\text { TLC }(1) \\
\text { TLC (\% pred) } \\
\text { RV (1) } \\
\text { RV (\% pred) } \\
\text { FEV }(1) \\
\text { FEV } / \mathrm{VC}_{1}(\% \text { pred }) \\
\text { sGaw }\left(\mathrm{s}^{-1} \mathrm{kPa}^{-1}\right) \\
\text { sGaw (\% pred) }\end{array}$ & $\begin{array}{c}5.5(1.4) \\
95(12) \\
1.0(0.6) \\
63(25) \\
3.2(0.7) \\
93(5) \\
1.35(0.36) \\
110(31)\end{array}$ & $\begin{array}{c}5 \cdot 5(1 \cdot 4) \\
96(11) \\
1 \cdot 2(0 \cdot 6) \\
70(28) \\
3 \cdot 3(0 \cdot 8) \\
96(5) \\
1 \cdot 41(0 \cdot 56) \\
117(55)\end{array}$ \\
\hline
\end{tabular}

TLC-total lung capacity; RV-residual volume; FEV $_{1}$ fLC-total lung capacity; RV-residual volume; FeV $_{1}$ vital capacity; sGaw-specific airways conductance; \% predvital capacity; sGaw-specific air 
Table 3 Baseline specific airways conductance (sGaw) and carbachol dose producing a decrease in specific airways conductance by $35 \%\left(P D_{35}\right)$ when the patients were hypothyroid and subclinically hyperthyroid

\begin{tabular}{|c|c|c|c|c|}
\hline \multirow[b]{2}{*}{$\begin{array}{l}\text { Patient } \\
\text { No }\end{array}$} & \multicolumn{2}{|c|}{ Hypothyroid } & \multicolumn{2}{|l|}{ Hyperthyroid } \\
\hline & $\begin{array}{l}s G a w \\
\left(s^{-1} k P a\right)\end{array}$ & $\begin{array}{l}P D_{35}^{\star} \\
(\mu g)\end{array}$ & $\begin{array}{l}s G a w \\
\left(s^{-1} k P a^{-1}\right)\end{array}$ & $\begin{array}{l}P D_{35} \star \\
(\mu g)\end{array}$ \\
\hline 1 & $1 \cdot 13$ & 157 & 0.78 & $>1260^{\star}$ \\
\hline 2 & 1.42 & 44 & 0.82 & 165 \\
\hline 3 & 1.02 & 80 & 1.06 & 181 \\
\hline 4 & 0.75 & 150 & 0.87 & 1019 \\
\hline 5 & $2 \cdot 20$ & 207 & $1 \cdot 81$ & 578 \\
\hline 6 & 1.34 & 105 & 1.22 & 151 \\
\hline 7 & $1 \cdot 21$ & 91 & 1.08 & 224 \\
\hline 8 & 1.32 & 92 & $1 \cdot 88$ & 77 \\
\hline 9 & $1 \cdot 19$ & 135 & 1.98 & 60 \\
\hline 10 & 1.74 & 104 & 1.34 & 78 \\
\hline 11 & 1.50 & 37 & $2 \cdot 65$ & 49 \\
\hline $\begin{array}{l}\text { Geometric } \\
\text { mean }\end{array}$ & & 97 & & 192 \\
\hline
\end{tabular}

*A $\mathrm{PD}_{35}$ of $1260 \mu \mathrm{g}$ was used for calculating the geometric mean.

\section{Discussion}

The results of this study show significantly higher $\mathrm{PD}_{35}$ values when the patients were mildly hyperthyroid than when they were hypothyroid, suggesting that bronchial reactivity is increased in hypothyroidism. This contrasts with observations in asthmatic patients, in whom hypothyroidism has been associated with a reduction in bronchial reactivity. The effects of hypothyroidism on the bronchial reactivity of non-asthmatic subjects are probably of no clinical relevance since none of our patients reported any respiratory symptoms when their thyroid state was altered.

Bronchial reactivity was assessed from the change in sGaw, a measurement that is more sensitive but less reproducible than indices obtained from a forced expiration. We did not use indices from a forced expiratory manoeuvre as a change in thyroid state may affect these indices by altering the maximum respiratory muscle power. ${ }^{131819}$ Myopathy may also occur in acute hypothyroidism. ${ }^{20}$ The mean interstudy coefficient of variation in the control group was $8 \%$, which is similar to values from other laboratories. ${ }^{21}$ Change in thyroid state had no effect on mean baseline sGaw, but the variation in measurements between the two occasions was greater in the thyroid patients than in the control group. This is not surprising because hypothyroid patients are usually less good at panting in the body plethysmograph, so that their sGaw measurements are likely to vary to a greater extent than those of the euthyroid controls. In this study thyroid state was changed quickly and the effect of hypothyroidism on bronchial reactivity may be greater after a longer period of thyroid deficiency. Our results may not therefore apply to longstanding hypothyroidism.

Our findings support the data of Villa et al, ${ }^{15}$ who observed an increase in bronchoconstrictor response to inhaled carbachol in congenitally hypothyroid non-asthmatic children after they had been without replacement treatment for one month. In non-asthmatic subjects Irwin et $a l^{11}$ and Roberts et $a l^{12}$ found no significant difference in bronchial reactivity between the overtly hyperthyroid and the euthyroid state. These authors expressed bronchial reactivity by indices obtained from forced expirations. In contrast, Israel $e t$ al $^{14}$ found that hyperthyroidism decreased non-specific bronchial reactivity in patients with either mild airways obstruction or no pulmonary disease. Interestingly, they were unable to show any change in $\mathrm{FEV}_{1}$ in response to carbachol challenge when euthyroidism was restored, whereas there was a significant change in bronchial reactivity when this was monitored as change in sGaw.

The biochemical basis of the relation between thyroid function and bronchial reactivity is not clear. Theoretically, thyroid deficiency might enhance bronchial reactivity by reducing the amount of circulating catecholamines or by decreasing bronchial sensitivity to catecholamines. Although some support for such an interaction exists in the older reports, recent studies suggest that the activity of the sympathetic nervous system is not enhanced by thyroid hormone; in fact, sympathetic activity appears to be decreased in hyperthyroidism and increased in thyroid deficiency. ${ }^{22-24}$ Harrison and Tattersfield ${ }^{25}$ showed an inverse relation between the level of thyroid function and the airway beta adrenergic responsiveness in non-asthmatic subjects. A thyroid-sympathetic interaction cannot therefore explain our findings. Other mechanisms have been proposed to account for the link between thyroid function and bronchial reactivity. Hyperthyroidism increases the conversion of hydrocortisone to its inactive 11-ketonic derivative and hypothyroidism decreases it. ${ }^{26-28}$ Hoult and Moore $^{29}$ suggested that hyperthyroidism worsens asthma by decreasing the pulmonary breakdown of prostaglandins, most probably because of decreased levels of the enzyme prostaglandin 15-hydroxydehydrogenase. Settipane $e t a l^{4}$ suggested that hyperthyroidism causes an overall decrease in cyclic AMP and so aggravates asthma. We conclude that the net effect of these hormone related mechanisms on bronchial reactivity is different in the asthmatic and the non-asthmatic bronchial tree.

1 Elliot CA. Occurrence of asthma in patients manifesting evidences of thyroid dysfunction. Am J Surg 1929;7: 333-7.

2 Bush RK, Ehrlich EN, Reed CE. Thyroid disease and asthma. J Allergy Clin Immunol 1977;59:398-401.

3 Editorial. Thyroid disease and asthma. Br Med J 1977;iv: $1173-4$.

4 Settipane GA, Schoenfeld E, Hamolsky MW. Asthma and hyperthyroidism. J Allergy Clin Immunol 1972;49:348-55.

5 Fitzpatrick WJF, Foreman PS, Porter EJB, Beckett AG. Hyperthyroidism and acute bronchial asthma. Br Med J 1984;288:314-5.

6 Ayres J, Clark TJH. Asthma and the thyroid [letter]. Lancet 1981 ;ii:1110-1.

7 Cockcroft DW, Silverberg JDH, Dosman JA. Decrease in non-specific bronchial reactivity in an asthmatic following treatment of hyperthyroidism. Ann Allergy 1978;41: treatme-3.

8 Rowe MS, MacKechnie HLN. Hypothyroidism with coexistent asthma: problems in management. South Med J 1984;77:401-2.

9 Lipworth BJ, Dhillon DP, Clark RA, Newton RW. Problems with asthma following treatment of thyrotoxicosis. Br J Dis Chest 1988:82:310-4.

10 Fedrick J, Baldwin JA. Thyroid disease and asthma [letter]. 
Br Med J 1977;ii:1539.

11 Irwin RS, Pratter MR, Stivers DH, Braverman LE. Airway reactivity and lung function in triiodothyronine-induced thyrotoxicosis. J Appl Physiol 1985;58:1485-8.

12 Roberts JA, McLellan AR, Alexander WD, Thomson NC. Effect of hyperthyroidism on bronchial reactivity in nonasthmatic patients. Thorax 1989;44:603-4.

13 Kendrick AH, O'Reilly JF, Laszlo G. Lung function and exercise performance in hyperthyroidism before and after treatment. $Q J$ Med 1988;68:615-27.

14 Israel RH, Poe RH, Cave WT, Greenblatt DW, DePapp Z. Hyperthyroidism protects against carbachol-induced bronchospasm. Chest 1987;91:242-5.

15 Villa MP, Cerimoniale G, Bernardi F, et al. Modification of nonspecific bronchial reactivity in hypothyroid children under different regimens of substitutive opotherapy. Pediatr Pulmonol 1986;2:353-7.

16 Wieshammer S, Keck FS, Waitzinger J, et al. Left ventricular function at rest and during exercise in acute hypothyroidism. Br Heart J 1988;60:204-11.

$17 \mathrm{Zar}$ JH. Biostatistical analysis. 2nd ed. Englewood Cliffs: Prentice Hall, 1984:24.

18 Freedman S. Lung volumes and distensibility, and maximum respiratory pressures in thyroid disease before and after treatment. Thorax 1978;33:785-90.

19 Martinez FJ, Bermudez-Gomez M, Celli BR. Hypothyroidism. A reversible cause of diaphragmatic dysfunction. Chest 1989;96:1059-63.

20 Kung AWC, Ma JTC, Yu YL, et al. Myopathy in acute hypothyroidism. Postgrad Med J 1987;63:661-3.
21 SEPCR Working Group "Bronchial Hyperreactivity" Guidelines for standardization of bronchial challenges with (nonspecific) bronchoconstrictor agents. Bull Eur Physiopathol Respir 1983;19:495-514.

22 Christensen NJ. Plasma noradrenaline and adrenaline in patients with thyrotoxicosis and myxedema. Clin Sci Mol , Med 1973;45:163-71.

23 Stoffer SS, Jiang NS, Gorman CA, Pikler GM. Plasma catecholamines in hypothyroidism and hyperthyroidism. $J$ Clin Endocrinol Metab 1973;36:587-9.

24 Coulombe P, Dussault JH, Walker P. Plasma catecholamine concentrations in hyperthyroidism and hypothyroidism. Metabolism 1976;25:973-9.

25 Harrison RN, Tattersfield AE. Airway response to inhaled salbutamol in hyperthyroid and hypothyroid patients before and after treatment. Thorax 1984;39:34-9.

26 Ruder H, Corvol P, Mahoudeau JA, Ross GT, Lipsett MB. Effects of induced hyperthyroidism on steroid metabolism in man. J Clin Endocrinol 1971;33:382-7.

27 Dazord A, Saez J, Bertrand J. Metabolic clearance rates and interconversion of cortisol and cortisone. JClin Endocrinol Metab 1972;35:24-34.

28 Kenny FM, Iturzaeta N, Preeyasombat C, Taylor FH, Migeon CJ. Cortisol production rate. VII. Hypothyroidism and hyperthyroidism in infants and children. J Clin Endocrinol 1967;27:1616-22.

29 Hoult JRS, Moore P. Thyroid disease, asthma, and prostaglandins [letter]. Br Med J 1978;i:366.

30 Quanjer $\mathrm{Ph}$, ed. Standardised lung function testing. Bull Eur Physiopathol Respir 1983;suppl 5. 